\title{
WHAT MOTIVATES HIGH SCHOOL STUDENTS IN CHOOSING A CAREER PATH IN THE HOSPITALITY INDUSTRY?
}

https://doi.org/10.47743/jopafl-2021-20-12

\author{
Lorin DRAGAN \\ Faculty of Economics and Business Administration, Alexandru Ioan Cuza University, \\ Iasi, Romania, \\ lorin.dragan@uaic.ro \\ Liliana MATA \\ Teacher Training Department, Vasile Alecsandri University, \\ Bacau, Romania, \\ liliana.mata@ub.ro \\ Loredana ANDRICI \\ Danubiana Technical College, \\ Roman, Romania \\ loredana.andrici@gmail.com \\ Adelina PANAITE \\ adelina.panaite97@gmail.com
}

\begin{abstract}
The current study analyzed the ideal workplace attributes sought by high school youth. Students in 4 classes were randomly assigned to control and intervention groups. The intervention consisted in watching a video with a fictitious employer that presents the realities of a real job, in both negative and positive scenarios. Students exposed to positive intervention did not show significant differences in identifying ideal workplace values. Students exposed to negative intervention were, however, influenced, altering the list of values sought at the ideal workplace by comparison with the control group.
\end{abstract}

\section{Introduction}

The teenagers enrolled în vocational training în Romania face various career decisions even prior to their graduation as several of them already work part time or as part of internships. Their definition of the ideal workplace seems to vary according to the literature. We examined 2 different paths as per literature review: on one hand we looked at the moral development as a key indicator of various moral choices, on the other hand we also reviewed other factors influencing the career path of adolescents.

\section{Moral development în teenagers}

In adolescence, the concept of fairness becomes more present and is widespread in various situations. However, adolescents are increasingly able to contextualize their moral judgment, in other words, to apply variations from one situation to another (Nucci, 2001). 
In a study that looked at adolescents' moral choices (to help someone or not to hurt someone), Nucci and Turiel (2009) determined a migration as teenagers age from an importance given to equality to an importance given to equity. The difference between equality and equity must be perceived in the same spirit of contextualization, so equity is a contextualized equality. In other words, fairness involves taking into account the differences in needs and status, this is the meaning of the migration from equality to equity. The same study also reveals an interesting U-shape evolution of moral growth, in the sense that the frequency of moral choices is higher in younger children and older adolescents than in early adolescents. The transition of early adolescents involved the non-uniform application of moral criteria (Nucci and Turiel, 2009). Another interesting approach followed the religious implications, as it studied adolescents (10-16 years) from different religions (Catholics, Calvinists, Orthodox, Jews, etc.) and noticed that they prioritize moral choices without being conditioned by a command or divine rule (Nucci and Turiel, 1993). In addition, the adolescents studied denied the possibility of an excuse for immoral behavior due to divine commandments, so they applied moral rules to explain religious approaches and not the other way around.

What constitutes morality as mentioned in the studies of adolescent morality is a legitimate question in the literature, and the different approaches have been analyzed by Hart and Carlo (2005). They distinguish between a few large schools of thought. Two schools of thought though seem to be the most relevant: Kohlberg's (1984) aims to study adolescents' understanding of moral concepts such as rights and justice. Eisenberg-Berg (1979) analyzes prosocial attitudes and the emotional components of morality. There is an interesting conclusion of Weiss's (1982) study on understanding the processes involved in moral thinking. They concluded that those adolescents with the least understanding are also the ones who use morality the most in their decisions, thus suggesting that morality can be more effective when adopted without too deep a dissection.

Positive psychology school of thought lists, among other things, valuable moral experiences, in addition to happiness, two moral aspects: positive individual traits and "civic virtues and institutions that determine individuals to be better citizens." (Seligman and Csikszentmihalyi, 2014). McAdams (2015) states that morality, personality and selfidentity are the most important 3 elements of the personal narrative created in late adolescence. Padilla Walker and Nelson (2017) exploit Erikson's ideas that the moral identity of late adolescents is the essential goal of both moral and identity development.

\section{Career choices}

There are a number of other factors besides the moral development influencing career choices în adolescents. One relevant study refers to their personality and their self esteem as key indicators of career choice but it also found that perceived social support does not influence the career indecision, but it influences self esteem which might play a role în career decision (Macionetti, 2014). În the same spirit, another research created a taxonomy of difficulties în career decision making. It split the decision making into 2 phases: (i) the one prior to the decision making when lack of readiness plays a central role and (ii) the one during the process of decision making itself when lack of information and inconsistent information plays a relevant role (Gati et al., 1996). Apparently, the motivation for a certain career choice is another key factor studied în the literature. One study found 
that the lack of motivation decreases with age and the late teenagers are influenced by intrinsic and extrinsic motivations. The intrinsic motivations can be associated with positive emotions, creativity, academic implications or pleasure to read while the extrinsic relate to the environmental motivators (Panisoara et al., 2013)

\section{Research Methodology}

In line with previous research that looked at intrinsic or extrinsic motivational factors (Johnson and Monserud, 2010) that generally showed intrinsic motivations in youth choices, we decided to investigate how exposure to a positive or negative professional situation influences the assessment of the attributes of the ideal job. For students in rural areas, as they were the subject of our research, we know that they are more subject to reflection than those in privileged backgrounds to almost automatically take jobs corresponding to their social status (Laughland-Booy et al., 2014 ).

We formulated the following working hypotheses:

H01 There is no difference between the control group and the negative intervention group in terms of perception of the values of the ideal job;

H11 There is a difference between the control group and the negative intervention group in terms of perception of the values of the ideal job;

H02 There is no difference between the control group and the positive intervention group in terms of perception of the values of the ideal job;

H12 There is no difference between the control group and the positive intervention group in terms of perception of the values of the ideal job;

H03 The share of attributes categorized as moral values does not change between the control group and the negative intervention group;

H13 The share of attributes categorized as moral values does change between the control group and the negative intervention group;

H04 The share of attributes categorized as moral values does not change between the control group and the positive intervention group;

H14 The share of attributes categorized as moral values does change between the control group and the positive intervention group.

The research methodology was based on an experiment aimed at assessing the students' morality în terms of choosing a career path. In the first phase, the subjects were selected among 9th and 10th grades, from a Technical College în a mid-sized Romanian town. The age groups were 15-17 years, the classes are relatively uniform, high school, most students come from rural areas. The distribution of the subjects in the control group and in the experimental groups was done randomly. Random Lists software was used for randomization. Randomization was done using the multistage randomization method (indirect selection of the individuals that make up the sample through the selection of the groups to which they belong). 
Following randomization, 4 control groups and 4 intervention groups resulted. In all the classes that were selected, before actually carrying out the experiment, the teacher explained to the students the purpose of the research, namely to find out the "professional wishes of the students from the technological schools" for which they will have to fill in a form. To collect the answers regarding the attributes of the "Ideal job" 4 types of forms with the same requirements were used: form C1 was distributed to classes X B and IX C for the control groups, form $\mathrm{N} 1$ for the intervention groups from the same classes, which were presented with a negative scenario ( $\mathrm{N}$ stands for negative), form $\mathrm{C} 2$ was distributed in classes X A and IX A for the control groups, form P2 for the intervention groups from the same classes, which were presented with a positive scenario . The answers were collected on the basis of an electronic form. The content of the form was aimed at: class, gender (female or male) and the open-ended question "How do you imagine the ideal job for you?"

In the first stage, the control groups were asked to respond to the form received, namely to write about the attributes of the ideal job. Firstly, the control groups filled in the forms, afterwards before presenting the film to the students, the teacher informed the students about a scenario regarding the research team who interviewed a "potential employer". In the video to be watched it is his answer about his work environment and expectations from the "future employee". The teacher, based on the same scenario, explains to the students that he "omitted" the presentation of the film from the very beginning, in order to give the students the confidence that there is no difference between the two groups. In the negative scenario, Stelian Caraion, the manager of a restaurant in Galați, describes it as a mid- luxury one with an average of 400 customers per day. The restaurant currently has 10 chefs and 15 waiters. The salary conditions are motivating, above the average of similar positions în Galati. Due to the high workload, stress and pressure, negative motivation is the most used among employees. Although it is a pandemic, in the proposed scenario the restaurant aims to increase its team.

In the positive scenario, the restaurant is located in a mountainous area. It has an average of 200 customers per day, a mid range clientele, currently the manager Ionica Negresco has a team of 6 chefs and 10 waiters. Salary packages are within the market average, and the fundamental principle on which the restaurant bases its activity is "mutual respect" between employees, regardless of the situation. The aim is to increase the team, and the candidate must correspond to the team's profile.

At the end of the video, the teacher also asks the intervention groups to fill in the form. In the 10B grade, the experiment was performed face to face, due to the physical presence of students at school, out of a total of 25 students, there were 18 girls and 7 boys, the control group consisted of 13 students and the intervention group of 12 students, the groups being relatively homogeneous. Out of a total of 25 students recruited for the experiment, due to the pandemic situation in which the town was at the date of the experiment (March 30, 2021), namely the town was in a red code situation, the actual attendance at school was 18 students, of which 14 girls and 3 boys, $72 \%$ of the class. Out of the total number of students present, the response rate was $100 \%$. The control group was represented by 11 students, of which 3 boys, and the intervention group of 7 students, of which 1 boy. For the 10A grade, the experiment was performed face to face, with the presence of students at school, out of a total of 21 students, the girls were 11 and the boys 10, the control group consisted of 11 students and the intervention one of 10 students, the 
groups being relatively homogeneous. Out of a total of 21 students recruited for the experiment, on March 30, 2021, the date of the experiment, the actual attendance at school was 18 students, of which 8 girls and 10 boys, $86 \%$ of the class. Out of the total number of students present, the response rate was $100 \%$. The control group was represented by 7 students, of which 4 boys, and the intervention group of 11 students, of which 6 boys. The intervention group was shown the film with a positive script. All responses collected were in electronic format.

In the 9C grade, the experiment was conducted online, on the Google Classroom platform, out of a total of 29 students, the girls were 16 and 13 boys, the control group consisted of 15 students and the intervention group of 14 students, the groups being relatively homogeneous. Out of a total of 29 students recruited for the experiment, on March 30, 2021, the date of the experiment, the attendance on the Google Classroom platform was 20 students, of which 12 girls and 8 boys, 69\% of the class. Out of the total number of students present, the response rate was 100\%. The control group consisted of 13 students, of which 6 boys, and the intervention group of 7 students, of which 2 boys. The intervention group watched the film with a negative script. All responses collected were in electronic format.

In the 9A grade, the experiment was conducted online, with the presence of students on the Google Classroom platform, out of a total of 25 students, the girls were 10 and the boys 15,, the control group consisted of 13 students and the intervention one of 12 students, the groups being relatively homogeneous. Out of a total of 21 students recruited for the experiment, on March 31, 2021, the date of the experiment, the actual presence on the Google Classroom platform was 17 students, of which 7 girls and 10 boys, 68\% of the class. Out of the total number of students present, the response rate was $100 \%$. The control group consisted of 9 students, of which 6 boys, and the intervention group of 8 students, of which 4 boys. The intervention group was shown the film with a positive script. All responses collected were in electronic format.

It was found that all control groups, which did not watch any films, requested additional information on what should be included in the "ideal workplace", and the intervention groups, who watched the films, regardless of whether they were positive. or negative, did not ask for other information, their responses were much more spontaneous, the waiting time for submitting the completed form was shorter. For almost half of the students targeted în the experiment, the classes took place online, the teacher involved in the experiment could not notice the students' reactions after watching the film, in the faceto-face classes, the reactions to watching the film with a positive script were visually imperceptible. watching the film with a negative script, the reactions of some students indicate a slight disapproval of the script presented.

\section{Research results}

First of all, the online answers, as well as the handwritten ones, were centralized and analyzed with the help of the atlas.ti qualitative analysis software. The coding activity was not based on predefined codes but these codes, which reflected the attributes of the studied variables, were defined as the coding was performed, depending on the open answers of the respondents. It is the in-vivo coding technique. The result was a number of 9 attributes searched for in relation to a job. We list them in the table below. 
Figure 1. Codes corresponding to qualitative analysis for current research

\begin{tabular}{|c|c|c|c|c|c|}
\hline & & $\begin{array}{l}{[\mathrm{C} C 1} \\
\square 2 @ 51\end{array}$ & $\begin{array}{l}\mathrm{CDC2} \\
\mathrm{D} 1 \odot 26\end{array}$ & $\begin{array}{l}{[\mathrm{D} \text { N1 }} \\
\square 2 \bigodot 19\end{array}$ & $\begin{array}{l}{[0 \text { P2 }} \\
\square 1 \bigodot 19\end{array}$ \\
\hline colegialitate & (1) 35 & 10 & 5 & 8 & 12 \\
\hline implicare si provocari profesionale & (1) 12 & 4 & 2 & 3 & 3 \\
\hline$\diamond$ integritate & (9) 1 & & & 1 & \\
\hline$>$ invatare si dezvoltare profesionala & (1) 14 & 4 & 4 & 2 & 4 \\
\hline mediu fizic placut & (1) 36 & 12 & 9 & 7 & 8 \\
\hline recompense materiale & (1) 28 & 10 & 5 & 4 & 9 \\
\hline$\checkmark$ relaxare \& placere & (4.) 41 & 15 & 14 & 6 & 6 \\
\hline$\nabla$ respect & (1) 14 & 5 & 1 & 3 & 5 \\
\hline$\nabla$ stabilitate & (4) 3 & 1 & 1 & & 1 \\
\hline Totals & & 61 & 41 & 34 & 48 \\
\hline
\end{tabular}

Translation from Romanian in the above order: collegiality, involvement and professional challenges, integrity, learning and professional development, pleasant physical environment, material rewards, relaxation \& pleasure, respect and stability.

Of these, we grouped as attributes with moral resonances, the following 4: collegiality, learning and professional development, integrity and respect. For the analysis of the first set of hypotheses, we performed an analysis of variance (ANOVA) on the control group C1, respectively on the negative intervention group N1.

Table 1 Descriptive analysis of groups for C1 / N1

\begin{tabular}{|c|c|c|c|c|}
\hline Groups & Count & Sum & Average & Variance \\
\hline collegiality & 2 & 18 & 9 & 2 \\
\hline involvement_professional_challenges & 2 & 7 & 3.5 & 0.5 \\
\hline integrity & 2 & 1 & 0.5 & 2 \\
\hline learning_personal_development & 2 & 6 & 3 & 12.5 \\
\hline pleasant_physical_environment & 2 & 19 & 9.5 & 18 \\
\hline material rewards & 2 & 14 & 10.5 & 40.5 \\
\hline relaxation & 2 & 21 & 4 & 2 \\
\hline respect & 2 & 8 & 1 & 0.5 \\
\hline
\end{tabular}


Table 2 Analysis of the variance between control group C1 and negative intervention group N1

\begin{tabular}{|c|c|c|c|c|c|c|}
\hline Source of Variation & SS & df & MS & F & P-value & F crit \\
\hline Between Groups & 235.1111 & 8 & 29.38889 & 3.369427 & 0.044439 & 3.229583 \\
\hline Within Groups & 78.5 & 9 & 8.722222 & & & \\
\hline Total & 313.6111 & 17 & & & & \\
\hline
\end{tabular}

Given the classical statistical hypotheses and the significance threshold $\alpha=0.05$ and the decision rule, if $\operatorname{sig}>\alpha$ the hypothesis $\mathrm{H} 01$ is not rejected, and if $\operatorname{sig}<\alpha$, then the hypothesis $\mathrm{H} 01$ is rejected. The value sig $=0.04<\alpha=0.05$, in conclusion the hypothesis $\mathrm{HO}$ is rejected. It can be stated with a probability of $95 \%$ that the hypothesis of equality of means on groups is rejected, so the characteristics resulting from the interview differ significantly between the people who were in control group 1 and the group who were negatively influenced. In the same way, we proceeded to the analysis of the second set of hypotheses (table 3 ). Here, having the classical statistical hypotheses, the significance threshold $\alpha=0.05$ and the decision rule, if sig $>\alpha$ does not reject the hypothesis H01, and if $\operatorname{sig}<\alpha$, then the hypothesis $\mathrm{H} 02$ is rejected. The value $\operatorname{sig}=0.15>\alpha=0.05$, in conclusion the hypothesis $\mathrm{HO}$ is not rejected. It can be stated with a probability of $95 \%$ that the hypothesis of equality of means on groups is not rejected, so the characteristics resulting from the interview do not differ significantly between the people who were in control group 1 and the group who were positively influenced.

Table 3 Analysis of the variance between control group C2 and positive intervention group N2

\begin{tabular}{|c|c|c|c|c|c|c|}
\hline Source of Variation & SS & df & MS & F & P-value & F crit \\
\hline Between Groups & 74.375 & 3 & 24.79167 & 3.051282 & 0.154664 & 6.591382 \\
\hline Within Groups & 32.5 & 4 & 8.125 & & & \\
\hline Total & 106.875 & 7 & & & & \\
\hline
\end{tabular}

For testing the following two sets of hypotheses, we considered the attributes with moral resonances, namely: collegiality, learning and professional development, integrity and respect. We determined from the frequency table the weight of each value from those mentioned above. We translated the percentage values into absolute values and the following table resulted. 
Table 4 Percentage values translated into absolute values for variables connected with the moral attributes of a job

\begin{tabular}{|c|c|c|c|c|}
\hline & C1 & C2 & N1 & P2 \\
\hline ○ colegialitate & 16.39 & 12.2 & 23.53 & 25 \\
\hline ○ integritate & 0 & 0 & 2.94 & 0 \\
\hline ○ invatare și dezvoltare profesionala & 6.56 & 9.76 & 5.88 & 8.33 \\
\hline ○ respect & 8.2 & 2.44 & 8.82 & 10.42 \\
\hline
\end{tabular}

Using the analysis of variance for the values corresponding to the control group and those corresponding to the negative intervention group, the following results were generated.

Table 5 Analysis of the variant for the values of the moral attributes of the control groups C1, respectively of the negative intervention $\mathrm{N} 1$

\begin{tabular}{|c|c|c|c|c|c|c|}
\hline Source of Variation & SS & df & MS & F & P-value & F crit \\
\hline Between Groups & 369.5692 & 3 & 123.1897333 & 16.29763299 & 0.010448985 & 6.591382116 \\
\hline Within Groups & 30.235 & 4 & 7.55875 & & & \\
\hline Total & 399.8042 & 7 & & & & \\
\hline
\end{tabular}

The value $\operatorname{sig}=0.01<\alpha=0.05$, in conclusion the hypothesis $\mathrm{H} 03$ is rejected. It can be stated with a 95\% probability that the hypothesis of equality of means by groups is rejected, so the characteristics resulting from the interview differ significantly between the people who were in control group 1 and the group who were negatively influenced, in terms of regarding the characteristics of morality in the workplace.For the last set of hypotheses, respectively the analysis of the variance for the values corresponding to the control group and those corresponding to the positive intervention group, the following results were generated.

Table 6 Analysis of the variant for the values of the moral attributes of the control groups C2, respectively of positive intervention $P 2$

\begin{tabular}{|c|c|c|c|c|c|c|}
\hline Source of Variation & SS & df & MS & F & P-value & F crit \\
\hline Between Groups & 357.6810375 & 3 & 119.2270125 & 4.154879244 & 0.101250913 & 6.591382116 \\
\hline Within Groups & 114.78265 & 4 & 28.6956625 & & & \\
\hline Total & 472.4636875 & 7 & & & & \\
\hline
\end{tabular}


The value sig $=0.1>\alpha=0.05$, in conclusion the hypothesis $\mathrm{H} 04$ is accepted. It can be stated with a 95\% probability that the hypothesis of equality of means by groups is not rejected, so the characteristics resulting from the interview do not differ significantly between the people who were in control group 1 and the group who were positively influenced, in terms of morality characteristics in the workplace.

\section{Discussions and conclusions}

Following the statistical analysis, performed with the Atlas.ti and SPSS programs, we followed the effect of the positive or negative intervention explained in the methodology. It was interesting to note that the influence on the respondents existed only in the case of negative intervention. Thus, the students who watched the video with the potential employer describing mostly unfavorable working conditions changed their assessment of the ideal job compared to the control group both in terms of total values taken into account and in terms of moral aspects.

Similarly, the analysis also revealed the lack of influence of young people's exposure to a positive scenario, with respondents not changing their general or moral values when exposed to a clip with an employer who described predominantly positive conditions at the workplace the work. The most relevant evolution in terms of general values associated with employment in the case of the negative intervention group was the increase in the importance of collegiality from $16.39 \%$ to $23.53 \%$ (table 7 ). It seems that a collegial, supportive environment is able to counterbalance a relatively hostile environment. Very interestingly, the relative importance of material rewards decreased (from $16.39 \%$ to $11.77 \%$ ) and of relaxation and pleasure at work (from $24.59 \%$ to $17.65 \%$ ).

Table 7 Evolution of the share of general values associated with the ideal job in the case of control group C1 and negative intervention group N1

\begin{tabular}{|c|c|c|}
\hline & $\begin{array}{c}\mathrm{C} 1 \\
\mathrm{Gr}=51 ; \mathrm{GS}=2\end{array}$ & $\begin{array}{c}\mathrm{N} 1 \\
\mathrm{Gr}=19 ; \mathrm{GS}=2\end{array}$ \\
\hline colegialitate & $16.39 \%$ & $23.53 \%$ \\
\hline implicare și provocari profesionale & $6.56 \%$ & $8.82 \%$ \\
\hline integritate & $0.00 \%$ & $2.94 \%$ \\
\hline invatare și dezvoltare profesionala & $6.56 \%$ & $5.88 \%$ \\
\hline mediu fizic placut & $19.67 \%$ & $20.59 \%$ \\
\hline recompense materiale & $16.39 \%$ & $11.77 \%$ \\
\hline relaxare \& placere & $24.59 \%$ & $17.65 \%$ \\
\hline respect & $8.20 \%$ & $8.82 \%$ \\
\hline stabilitate & $1.64 \%$ & $0.00 \%$ \\
\hline Totals & $100.00 \%$ & $100.00 \%$ \\
\hline
\end{tabular}


Regarding the moral values, here the evolution was significant for collegiality and integrity (from $52.63 \%$ to $57.14 \%$, respectively from $0 \%$ to $7.14 \%$ ) to the detriment of learning and professional development and respect. (Table 8)

Table 8 Evolution of the weight of moral values associated with the ideal job in the case of control group $\mathrm{C} 1$ and negative intervention group $\mathrm{N} 1$

\begin{tabular}{|c|c|c|}
\hline & $\begin{array}{c}\mathrm{C} 1 \\
\mathrm{Gr}=51 ; \mathrm{GS}=2\end{array}$ & $\mathrm{Gr}=19 ; \mathrm{GS}=2$ \\
\hline collegiality & $52.63 \%$ & $57.14 \%$ \\
\hline integrity & $0.00 \%$ & $7.14 \%$ \\
\hline learning and professional development & $21.05 \%$ & $21.43 \%$ \\
\hline respect & $26.32 \%$ & $100.00 \%$ \\
\hline Totals & $100.00 \%$ & $29 \%$ \\
\hline
\end{tabular}

Analyzing the Sankey diagram in figure 2, we could see that most students tend to be attracted by those values related to an easy and pleasant workplace such as relaxation, pleasant environment, collegiality but also the material rewards seem to be of crucial importance.

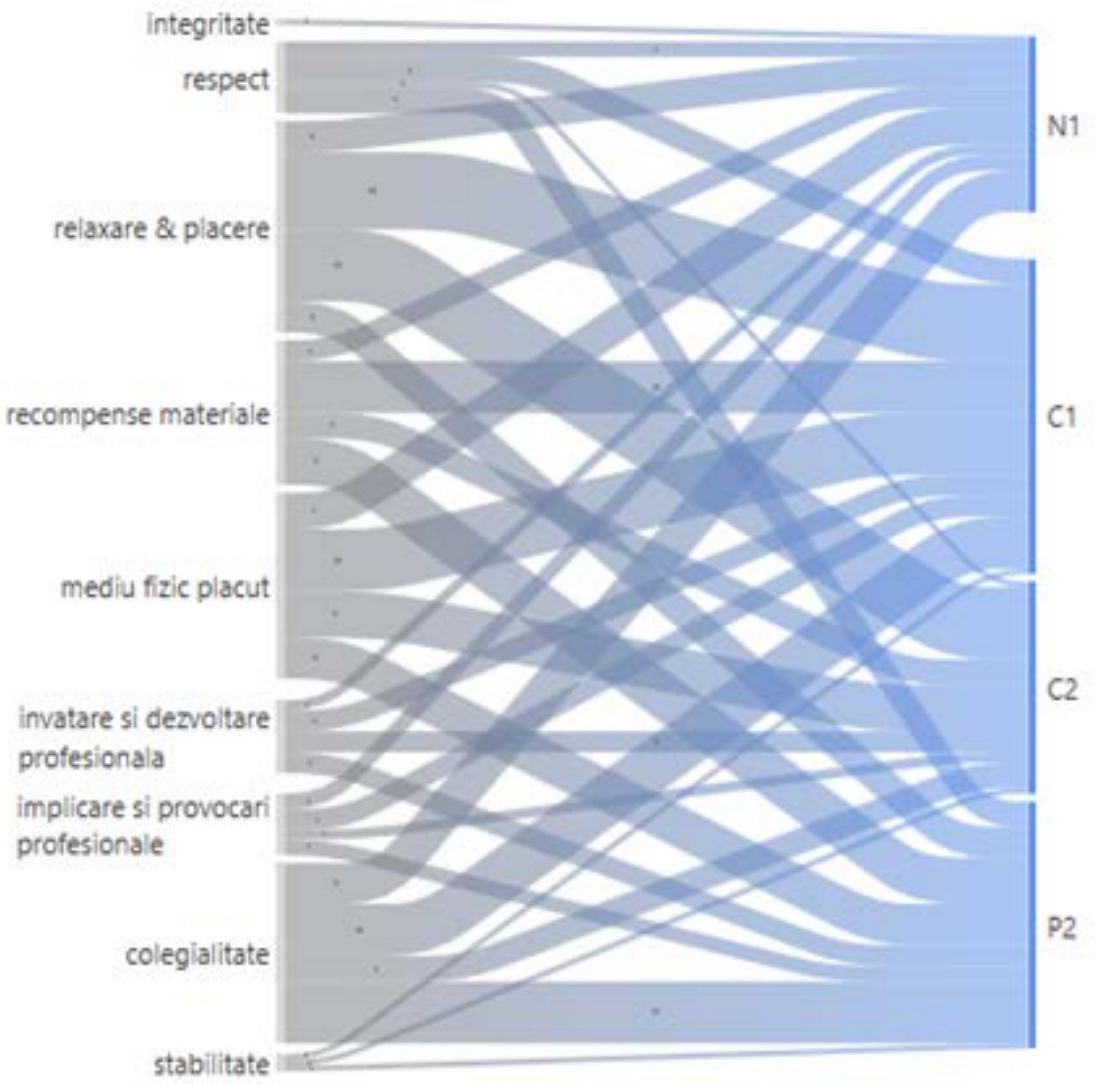

Figure 2 Sankey diagram of all cumulative values on all groups studied 


\section{Limitations and future research}

The study had as its essential limit, the unexpected suspension of on site teaching dictated by the current pandemic context. Basically, it affected the response rate, interest, but also the random distribution of students in the control group, because everything was done in the last week of school, the participation and interest of students were minimal. Ideally, we would have preferred to randomly distribute respondents into a single control group, but being few in school and few classes available, we resorted to two control groups to ensure comparability: control and intervention groups being from the same classes. It would be interesting to resume the experiment by randomizing the entire school population, ensuring a uniform distribution by gender, but also by high school / vocational school. It may be interesting for a future study to find out from students how they see the future, în the context of artificial intelligence and automation taking over relevant parts of the hospitality industry. Scenarios such as delivering the menu by drone at home, or taking over the reception of a hotel by a robot Sofia, etc., will be fashionable. There are already branded hotel chains, where most hotel functions are delivered through robotics and artificial intelligence. In this context, it would be interesting to study how these students perceive this threat.

\section{References}

1. Eisenberg-Berg, Nancy. Development of Children's Prosocial Moral Judgment. Developmental Psychology 15.2 (1979): 128-37. https://doi.org/10.1037/0012-1649.15.2.128.

2. $\quad$ Gati, I., Krausz, M., \& Osipow, S. H. (1996). A taxonomy of difficulties in career decision making. Journal of Counseling Psychology, 43(4), 510-526. https://doi.org/10.1037/0022-0167.43.4.510

3. Hart, Daniel, and Gustavo Carlo. Moral Development in Adolescence. Journal of Research on Adolescence 15.3 (2005): 223-33.

4. Johnson, M. K., \& Monserud, M. A. (2010). Judgments about work and the features of young adults’ jobs. Work and Occupations, 37(2), 194-224. https://doi.org/10.1177/0730888410365973

5. $\quad$ Kohlberg, Lawrence. The Psychology of Moral Development Nature and Validity of Moral Stages. San Francisco: Harper \& Row, 1984. Print.

6. $\quad$ Laughland-Booÿ, J., Mayall, M., \& Skrbiš, Z. (2015). Whose choice? Young people, career choices and reflexivity re-examined. Current Sociology, 63(4), 586-603. https://doi.org/10.1177/0011392114540671

7. Marcionetti, J. (2014). Factors affecting teenagers' career indecision in southern Switzerland. Procedia-Social and Behavioral Sciences, 112, 158-166. https://doi.org/10.1016/j.sbspro.2014.01.1151

8. $\quad$ McAdams, Dan P. The Art and Science of Personality Development. Guilford, 2015. Print.

9. Nucci, Larry, and Elliot Turiel. Capturing the Complexity of Moral Development and Education. Mind, Brain, and Education 3.3 (2009): 151-59.

10. Nucci, L., \& Turiel, E. (1993). God's word, religious rules, and their relation to Christian and Jewish children's concepts of morality. Child Development, 64(5), 1475-1491. https://doi.org/10.1111/j.14678624.1993.tb02965.x

11. Padilla-Walker, Laura M., and Larry J. Nelson. Flourishing in Emerging Adulthood: Positive Development during the Third Decade of Life. Oxford UP, 2017. Print.

12. Pânişoară, G., Pânişoară, I. O., Lupaşcu, A., \& Negovan, V. (2013). Motivation for career in $\begin{array}{lllll}\text { teenagers. Procedia-Social and } & \text { Behavioral } & \text { Sciences, } & 78, & 104 .\end{array}$ https://doi.org/10.1016/j.sbspro.2013.04.259

13. Seligman, Martin E., and Mihaly Csikszentmihalyi. Positive Psychology: An Introduction. Flow and the Foundations of Positive Psychology (2014): 279-98. Print. 
14. Seligman, M. E., \& Csikszentmihalyi, M. (2014). Positive psychology: An introduction. In Flow and the foundations of positive psychology (pp. 279-298). Springer, Dordrecht. https://doi.org/10.1007/97894-017-9088-8_18

15. Weiss, R. J. (1982). Understanding moral thought: Effects on moral reasoning and decision making. Developmental Psychology, 18(6), 852. https://doi.org/10.1037/0012-1649.18.6.852 Creative Commons Attribution - Non Commercial - No Derivatives 4.0 International License. 
